\title{
Analysis of a potential coalburst phenomenon in different strata layers in underground coal mines
}

\author{
C Zhang University of New South Wales, Australia \\ I Canbulat University of New South Wales, Australia \\ F Tahmasebinia University of New South Wales, Australia \\ O Vardar University of New South Wales, Australia \\ S Saydam University of New South Wales, Australia
}

\begin{abstract}
Coalburst is referred to as the violent failure of overstressed coal, which has been recognised as one of the most critical dynamic failures in coal mines. This paper aims to analytically and numerically evaluate the energy transformation between the different strata and coal layers. An accurate closed-form solution is developed. Due to the complexity of the causes and mechanisms contributing to the coalburst occurrence, $3 D$ finite element modelling was developed to validate the suggested analytical assessments of rock/coalburst occurrence. The energy concept is emphasised in order to improve the understanding of the underlying mechanisms of coalburst. Only with enhanced understanding of the driving mechanisms, a reliable coalburst risk assessment can be achieved.
\end{abstract}

Keywords: coalburst, mechanisms, energy, numerical modelling

\section{Introduction}

Many researchers define rock/coalburst as a sudden, rapid rupture of the rock mass with a violent, explosive release of elastic/strain energy from the surface of an excavation, which is generally associated with a seismic event and produces rock particle ejections (Linkov 1996; Gong et al. 2012; Li et al. 2012; Cai 2013). The coalburst source is the mechanism that triggers or induces the damage mechanism noticeable on the excavated surface. The coalburst source is generally associated with a seismic event that can be performed at a wide range of local magnitudes, normally ranging from undetectable up to five (Ortlepp \& Stacey 1994). Indeed, mining-induced seismicity can reach reasonable values of ground velocity and acceleration, and in some cases its effects on the surface can be compared with low-intensity earthquakes (Cai 2013).

The mechanism that contributes to coalburst is a sudden release of the strain energy that has been stored above a critical level within the rock/coal mass. Part of this energy is consumed by fracture formation, and the remaining energy is transformed into kinetic energy (Wang \& Park 2001; Li et al. 2012). When the source is located close to the excavation surface, this kinetic energy causes the coal fragments to be ejected. When the source is located in a plane of weakness within the rock mass, the released energy induces shear displacements along the plane, which in turn produce vibrations that induce coal ejections when they reach the excavation boundaries (Ortlepp \& Stacey 1994).

Tarasov and Randolph (2008) have explained a number of special and inconsistent behaviours of hard rock at great depth that are directly related to rock failure mechanisms in deep excavations. They pointed out that shearing processes with unusually low friction are the main cause of the high-energy release of bursts. According to their frictionless mechanism, coal confined under high stress levels may increase its brittleness, instead of the expected increase of ductility, and may also increase the violence of the fracture process.

Under an energy-balance approach, the methods to predict coalburst risk are based on energy indexes such as energy release rate (ERR) (Cook 1983; Linkov 1996;), energy storage rate (ESR), strain energy storage index 
(WET) (Wattimena et al. 2012), potential energy of elastic strain (PES) or strain energy density (SED) (i.e. the elastic strain energy in a unit volume of the rock mass, which is calculated by the uniaxial compressive strength of the rock and its unloading tangential modulus; Wang \& Park 2001), and burst potential index (BPI) (Mitri et al. 1999).

Two critical aspects towards understanding coalburst are the potential of stress analyses of underground excavations and the grasp of the behaviour of rock materials. Salamon et al. (1984) applied the theory of elasticity to the problems in mining tabular deposits, and the study produced important theoretical results that were utilised as a solid component in other researchers' work. Until the 1960s, only an idea-elastic model and an ideal-plastic model was accessible and commonly applied in underground mining related issues to correspond to mathematical explanations of the behaviour of rock materials and predict deformation of underground excavations under external loads. Problems in underground mining operations, such as design of pillars and excavations, were analysed primarily using empirical rules based on phenomenological observations obtained by experienced miners and researchers. As a major and well-known safety issue in underground mines, coalburst along with other problems in mining operations were studied qualitatively due to inadequate experimental analysis of rock materials (Linkov 1996). The energy-based approach is one of the popular methods to determine the critical regions in the rock/coal mass structures. Cook et al. (1966) were one of the pioneers to consider the effect of the energy changes throughout the mining activities as well as excavations. (Salamon 1984) describes in great detail numerous energy magnitudes that are needed to assess the ERR. Namely, the work done by the external and body forces when acting through the induced displacements $(W)$, the strain energy content of the volume $(\mathrm{Vm})$ of the rock to be mined $\left(\mathrm{U}^{\prime}\right)$, the change in strain energy in the volume (V) of the system that remains unmined $(U)$, and the total work done by the contact and body forces on the permanent supports (Ws). The first sort of coalburst mechanism is concerned with the perception of energy release, since the coalburst is caused by a dynamic and unstable release of energy within the excessive stresses in the rock mass/coal during the mining process. In view of the energy contemplations, there are a variety of energy modules. Potential energy is the stored energy of a place in which held by coal, and there are two forms of potential energy being gravitational potential energy and elastic potential energy. Gravitational potential energy is the function of the vertical position or height. Strain energy is the energy stored in coal due to deformation, and the external work done on the coal in causing it to alter from its unstressed state which is usually transformed into strain energy.

As another component, kinetic energy is the energy possessed by coal in action. Mining activities change the status of potential and strain energies stored within the coal in the vicinity of excavations. The major source of energy in the system, around the excavation is the work done by the boundary loading and body forces (e.g. gravity). Energy is dissipated in several forms, including the strain energy change, the kinetic energy, loading on the support system if it is applied. It has been suggested that up to half of the source energy can be stored as elastic energy in the rock around the excavations if the far-field stresses remain constant and the rock mass is unsupported; and the remainder must be released or dissipated (Cook 1983; Peng 2008; Salamon 1984; Zhang et al. 2009). The released energy or residual energy is either transferred into kinetic energy or dissipated energy in non-elastic behaviour such as joint shear and fracturing. The unstable releases of potential energy of the rock around the excavations, mainly in the form of kinetic energy, causes coalburst.

\section{$2 \quad$ Analytical approach}

An analytical method was developed to evaluate strain energy distributions between the engaged surfaces throughout different strata layers. The main concept to derive the following equations was extracted from the Ranzi and Gilbert (2015) and Ranzi et al. (2010). According to Ranzi and Gilbert (2015) the cross sectional analysis in the current paper is based on the assumption of the Euler-Bernoulli beam model. The strain distribution across the section can be calculated by $\varepsilon=\varepsilon_{r}-y \times \kappa$, where $\varepsilon_{r}$ is the strain at the reference point (which can determine at any point), $y$ is the distance between the selected point and location of the neutral axis of the cross section and $\kappa$ is the curvature across the section in different strata layers. A vector can be introduced by $K(D)$ which will be included the internal action $N$ (axial forces) and $M$ (internal moment). External loads, which might be due to the effect of the self-weight of the strata layers as well as 
the possible applied forces due to the vertical or horizontal displacement in the different layers, can induce the external axial force $N_{e}$ and external moment $M_{e}$. The relationship between the internal and external actions can be presented by:

$$
\begin{gathered}
\varepsilon=\left[\begin{array}{l}
\varepsilon_{r} \\
\kappa
\end{array}\right] \\
r(\varepsilon)=\left[\begin{array}{l}
N \\
M
\end{array}\right] \\
r_{e}=\left[\begin{array}{l}
N_{e} \\
M_{e}
\end{array}\right] \\
r(\varepsilon)=r_{e}
\end{gathered}
$$

Equation (4) is the vector for strain.

By considering the nonlinear interactions, the presented equations can be re-written by:

$$
\begin{gathered}
r\left(\varepsilon^{(i+1)}\right)=r\left(\varepsilon^{(i)}\right)+r_{t}\left(\varepsilon^{(i)}\right) \times \Delta \varepsilon^{(i)}=r_{e} \\
r_{t}\left(\varepsilon^{(i)}\right) \times \Delta \varepsilon^{(i)}=r_{R}^{(i)} \\
r_{R}^{(i)}=r_{e}-r\left(\varepsilon^{(i)}\right) \\
\frac{\partial N\left(\varepsilon_{r}^{(i)}, \kappa^{(i)}\right)}{\partial \varepsilon_{r}} \times \Delta_{r}^{(i)}+\frac{\partial N\left(\varepsilon_{r}^{(i)}, \kappa^{(i)}\right)}{\partial \kappa} \times \Delta \kappa=N_{R}^{(i)} \\
N_{R}^{(i)}=N_{e}-N\left(\varepsilon_{r}^{(i)}, \kappa^{(i)}\right) \\
M_{R}^{(i)}=M_{e}-M\left(\varepsilon_{r}^{(i)}, \kappa^{(i)}\right)
\end{gathered}
$$

The entire of the equations can be represented by matrix format:

$$
\begin{gathered}
r_{t}\left(\varepsilon^{(i)}\right)=\left[\begin{array}{cc}
\frac{\partial N\left(\varepsilon_{r}^{(i)}, \kappa^{(i)}\right)}{\partial \varepsilon_{r}} & \frac{\partial N\left(\varepsilon_{r}^{(i)}, \kappa^{(i)}\right)}{\partial \kappa} \\
\frac{\partial M\left(\varepsilon_{r}^{(i)}, \kappa^{(i)}\right)}{\partial \mathcal{E}_{r}} & \frac{\partial M\left(\varepsilon_{r}^{(i)}, \kappa^{(i)}\right)}{\partial \kappa}
\end{array}\right] \\
\Delta \mathcal{E}^{(i)}=\left[\begin{array}{l}
\Delta \varepsilon_{r}^{(i)} \\
\Delta_{\boldsymbol{\kappa}^{(i)}}
\end{array}\right]
\end{gathered}
$$

(Changing strain and curvature).

$$
r_{R}^{(i)}=\left[\begin{array}{c}
N_{R}^{(i)} \\
M_{R}^{(i)}
\end{array}\right]
$$


The partial derivatives of $N$ and $M$ with respect to $\varepsilon_{r}$ and $\kappa$ can be re-arranged in a more practical form, recalling the definitions of internal actions as:

$$
\begin{gathered}
\frac{\partial N\left(\varepsilon_{r}^{(i)}, \kappa^{(i)}\right)}{\partial \varepsilon_{r}}=\int \frac{\partial \sigma}{\partial \varepsilon_{r}} d A \\
\frac{\partial N\left(\varepsilon_{r}^{(i)}, \kappa^{(i)}\right)}{\partial \kappa}=\int \frac{\partial \sigma}{\partial \kappa} d A \\
\frac{\partial M\left(\varepsilon_{r}^{(i)}, \kappa^{(i)}\right)}{\partial \varepsilon_{r}}=-\int y \frac{\partial \sigma}{\partial \varepsilon_{r}} d A \\
\frac{\partial M\left(\varepsilon_{r}^{(i)}, \kappa^{(i)}\right)}{\partial \kappa}=-\int y \frac{\partial \sigma}{\partial \kappa} d A
\end{gathered}
$$

Where the values of the stress depend on the constitutive models adopted for the materials and on the magnitude of the strain (Ranzi \& Gilbert 2015).

$$
\begin{aligned}
& \frac{\partial N\left(\varepsilon_{r}^{(i)}, \kappa^{(i)}\right)}{\partial \varepsilon_{r}}=\int \frac{\partial \sigma}{\partial \varepsilon_{r}} d A=\int \frac{\partial \sigma}{\partial \varepsilon} \times \frac{\partial \varepsilon}{\partial \varepsilon_{r}} d A=\int \frac{\partial \sigma}{\partial \varepsilon} \times \frac{\partial\left(\varepsilon_{r}-y \times \kappa\right)}{\partial \varepsilon_{r}} d A=\int \frac{\partial \sigma}{\partial \varepsilon} d A \\
& \frac{\partial N\left(\varepsilon_{r}^{(i)}, \kappa^{(i)}\right)}{\partial \kappa}=\int \frac{\partial \sigma}{\partial \kappa} d A=\int \frac{\partial \sigma}{\partial \varepsilon} \times \frac{\partial\left(\varepsilon_{r}-y \times \kappa\right)}{\partial \kappa} d A=-\int y \times \frac{\partial \sigma}{\partial \varepsilon} d A \\
& \frac{\partial M\left(\varepsilon_{r}^{(i)}, \kappa^{(i)}\right)}{\partial \varepsilon_{r}}=-\int y \times \frac{\partial \sigma}{\partial \varepsilon_{r}} d A=-\int y \times \frac{\partial \sigma}{\partial \varepsilon} \times \frac{\partial\left(\varepsilon_{r}-y \times \kappa\right)}{\partial \varepsilon_{r}} d A=-\int y \times \frac{\partial \sigma}{\partial \varepsilon} d A \\
& \frac{\partial M\left(\varepsilon_{r}^{(i)}, \kappa^{(i)}\right)}{\partial \kappa}=-\int y \times \frac{\partial \sigma}{\partial \varepsilon_{r}} d A=-\int y \times \frac{\partial \sigma}{\partial \varepsilon} \times \frac{\partial\left(\varepsilon_{r}-y \times \kappa\right)}{\partial \kappa} d A=\int y^{2} \times \frac{\partial \sigma}{\partial \varepsilon} d A \\
& \sigma=E \times \varepsilon_{\text {for }}|\varepsilon| \leq \varepsilon_{p} \text { (plastic strain) } \\
& \sigma=f_{p \text { for }}|\varepsilon|>\varepsilon_{p} \text { (plastic strain) } \\
& \frac{\partial \sigma}{\partial \varepsilon}=\frac{\partial(E \times \varepsilon)}{\partial \varepsilon}=E_{\text {for }}|\varepsilon| \leq \varepsilon_{p} \text { (plastic strain) } \\
& \frac{\partial \sigma}{\partial \varepsilon}=\frac{\partial\left(f_{p}\right)}{\partial \varepsilon}=0 \text { for }|\varepsilon|>\varepsilon_{p} \text { (plastic strain) } \\
& N\left(\varepsilon_{r}^{(i)}, \kappa^{(i)}\right)=\int \sigma d A=\sum_{j=1}^{n_{j}} \sigma\left(y_{j}, \varepsilon_{r}^{(i)}, \kappa^{(i)}\right) \times A_{j} \\
& M\left(\varepsilon_{r}^{(i)}, \kappa^{(i)}\right)=-\int y \sigma d A=-\sum_{j=1}^{n_{j}} y_{j} \times \sigma\left(y_{j}, \varepsilon_{r}^{(i)}, \kappa^{(i)}\right) \times A_{j} \\
& \frac{\partial N\left(\varepsilon_{r}^{(i)}, \kappa^{(i)}\right)}{\partial \varepsilon_{r}}=\int \frac{\partial \sigma}{\partial \varepsilon} d A=\sum_{j=1}^{n_{j}} \frac{\partial \sigma\left(y_{j}, \varepsilon_{r}^{(i)}, \kappa^{(i)}\right)}{\partial \varepsilon} \times A_{j}
\end{aligned}
$$




$$
\begin{aligned}
& \frac{\partial N\left(\varepsilon_{r}^{(i)}, \kappa^{(i)}\right)}{\partial \kappa}=-\int y \times \frac{\partial \sigma}{\partial \varepsilon_{r}} d A=-\sum_{j=1}^{n_{j}} y_{j} \times \frac{\partial \sigma\left(y_{j}, \varepsilon_{r}^{(i)}, \kappa^{(i)}\right)}{\partial \varepsilon} \times A_{j} \\
& \frac{\partial M\left(\varepsilon_{r}^{(i)}, \kappa^{(i)}\right)}{\partial \varepsilon_{r}}=-\int y \times \frac{\partial \sigma}{\partial \varepsilon_{r}} d A=-\sum_{j=1}^{n_{j}} y_{j} \times \frac{\partial \sigma\left(y_{j}, \varepsilon_{r}^{(i)}, \kappa^{(i)}\right)}{\partial \varepsilon} \times A_{j} \\
& \frac{\partial M\left(\varepsilon_{r}^{(i)}, \kappa^{(i)}\right)}{\partial \kappa}=\int y^{2} \times \frac{\partial \sigma}{\partial \varepsilon} d A=\sum_{j=1}^{n_{j}} y_{j}^{2} \times \frac{\partial \sigma\left(y_{j}, \varepsilon_{r}^{(i)}, \kappa^{(i)}\right)}{\partial \varepsilon} \times A_{j}
\end{aligned}
$$

Thus, by calculating stress and strain at the different points at the different layers of the overburden, the internal axial forces as well as internal moments can be calculated. By computing the internal actions, the amount of the strain energy in the system can be achieved. Since calculating the relevant elastic as well as plastic stress and strain might be complicated, thus, a numerical analysis is suggested to calculate and evaluate the amount of the stored as well as released energy in the system. Evaluating of the analytical approach can lead to a better understating of the interaction between the key elements in the current simulation. The kinetic energy, which is a combination of induced works in different layers which can cause moving layers as well as releasing kinetic energy to the different part of the mining structure, can be presented as:

$$
E_{\text {kinetic }}=\sum\left(\int\left(\delta_{x x} \cdot A_{x x} \cdot \varepsilon_{x x} \cdot l_{x}\right) d x+\int\left(\delta_{y y} \cdot A_{y y} \cdot \varepsilon_{y y} \cdot l_{y}\right) d y+\int\left(\delta_{z z} \cdot A_{z z} \cdot \varepsilon_{z z} \cdot l_{z}\right) d z\right)
$$

where:

$$
\begin{array}{lll}
\delta_{x x}, \delta_{y y}, \delta_{z z} & = & \text { stress components in the different directions. } \\
A_{x x}, A_{y y}, A_{z z} & = & \text { effective area in the different directions. } \\
\varepsilon_{x x} \cdot l_{x} & = & \text { the amount of the slip in } \mathrm{x} \text { direction. } \\
\varepsilon_{y y} \cdot l_{y} & = & \text { the amount of the slip in y direction. } \\
\varepsilon_{z z} \cdot l_{z} & = & \text { the amount of the slip in z direction. }
\end{array}
$$

The factor of $\left(\frac{E_{\text {kinetic }}}{E_{\text {strain }}}\right)^{\alpha}$ can be represented by:

$$
\left(\frac{E_{\text {kinetic }}}{E_{\text {strain }}}\right)^{\alpha}=\left(\sum \frac{\int\left(\delta_{x x} \cdot A_{x x} \cdot \varepsilon_{x x} \cdot l_{x}\right) d x}{E_{\text {strain }}}+\sum \frac{\int\left(\delta_{y y} \cdot A_{y y} \cdot \varepsilon_{y y} \cdot l_{y}\right) d y}{E_{\text {strain }}}+\sum \frac{\int\left(\delta_{z z} \cdot A_{z z} \cdot \varepsilon_{z z} \cdot l_{z}\right) d z}{E_{\text {strain }}}\right)^{\alpha}
$$

Equation (33) indicates how the slip in different directions can play a key role in releasing the stored energy in the different layers. The amount of the slip between the layers is partially either dependent on the joint properties or structural confinement in the free edges (for instance, the presences of geological structures such as faults, dykes, sandstone channels, joints, etc.). Underground excavations can result in stress concentration as well as stress redistributions on to face and adjacent pillars.

\section{$3 \quad$ Numerical modelling}

3D finite element modelling has been used in the current paper. As part of this study, a simple bord-and-pillar model to evaluate energy transmission in different strata layers has been developed. A Mohr-Coulomb (MC) material that presents a constant strength after failure, and a Mohr-Coulomb strain-softening material (Wang \& Park 2001; Sirait et al. 2013; Mortazavi \& Alavi 2013; Nie et al. 2014; Poeck et al. 2015) that can reach the peak strength and then decrease to a residual strength have been considered. It is suggested that 
the outcomes of the numerical modelling study together with the combination with other analytical techniques can be used to estimate both in situ stress as well as mining-induced stress, where it may result in identifying the coalburst prone areas in a mine site. Another aspect of this study is that it takes into account the influence of the third dimension which can play a key role in interpretation of the result. Developing 3D finite element (FE) models using dynamic solver (ABAQUS/Explicit (Dassault Systèmes Simulia Corp. 2012)), which is a convergence free solver, is one of the major advantages of the current simulations in comparison with the former simulations (Figure 1). The convergence free simulation is a simulation where it will be stopped the analysis due to the local failure on the simulated models. Moreover, Poeck et al. (2015) emphasised the advantages of the three dimensional FE modelling in comparison to $2 \mathrm{D}$ models when considering the correlation of energy release values. Table 1 lists the basic material properties used for overburden and coal material properties.

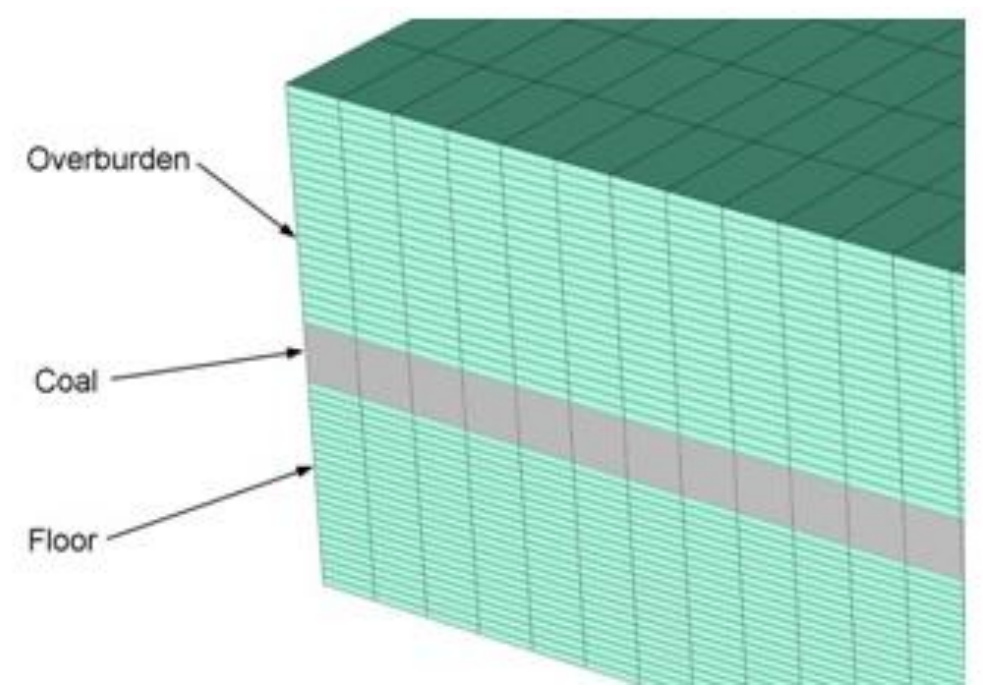

Figure 1 A sample of the developed finite element model

Table 1 Numerical modelling material properties (after Poeck et al. 2015)

\begin{tabular}{llllll}
\hline Material & $\begin{array}{l}\text { Density } \\
\left(\mathrm{kg} / \mathrm{m}^{3}\right)\end{array}$ & $\begin{array}{l}\text { Young's } \\
\text { modulus } \\
(\mathrm{GPa})\end{array}$ & $\begin{array}{l}\text { Poisson's } \\
\text { ratio }\end{array}$ & $\begin{array}{l}\text { Friction } \\
\text { angle }\left(^{\circ}\right)\end{array}$ & $\begin{array}{l}\text { Cohesion } \\
(\mathrm{MPa})\end{array}$ \\
\hline Overburden & 2,350 & 23.4 & 0.26 & - & - \\
\hline Coal & 1,313 & 3 & 0.2 & 23 & 1.69 \\
\hline
\end{tabular}

Table 2 lists the changes in cohesion, friction and dilation angles applied to the strain-softening material with associated levels of strain (Poeck et al. 2015). A simple bord-and-pillar panel layout in conjunction with different material properties, joint properties, and loading conditions were undertaken by Poeck et al. (2015). In order to comprehensively extend the Poeck et al.'s model (2015), a 3D pillar model that considers the different joint properties has been developed in this study. Consideration was also given to define a joint interface between the coal and overburden rock. 
Table 2 Softening parameters used in coal (Poeck et al. 2015)

\begin{tabular}{|c|c|c|c|c|c|}
\hline \multicolumn{2}{|c|}{ Cohesion } & \multicolumn{2}{|c|}{ Friction angle } & \multicolumn{2}{|c|}{ Dilation angle } \\
\hline $\begin{array}{l}\text { Axial } \\
\text { Strain }\end{array}$ & $\begin{array}{l}\text { Value } \\
\text { (MPa) }\end{array}$ & $\begin{array}{l}\text { Axial } \\
\text { Strain }\end{array}$ & $\begin{array}{l}\text { Value } \\
\left({ }^{\circ}\right)\end{array}$ & $\begin{array}{l}\text { Axial } \\
\text { Strain }\end{array}$ & $\begin{array}{l}\text { Value } \\
\left({ }^{\circ}\right)\end{array}$ \\
\hline 0 & 1.69 & 0 & 23 & 0 & 2 \\
\hline 0 & 1.54 & 0.00007 & 27.5 & 0.00007 & 10 \\
\hline 0 & 1.47 & 0.0001 & 30 & 0.01360 & 10 \\
\hline 0 & 0.2 & 1 & 30 & 0.01413 & 2 \\
\hline 1 & 0.2 & & & 1 & 2 \\
\hline
\end{tabular}

Based on the study by Poeck et al. (2015), the three variations of joint properties included in the study were fixed (or tie condition) where there is no slip between the rock and coal interface. The coal-rock interface slip (CS) is presented by Coulomb-slip parameters, and continuous yielding (CY) is presented by displacement softening parameters. Figure 2 shows the stress-strain behaviour of the CS and CY joints used in the coal-rock interface. Table 3 lists the parameters applied to each of the constitutive joint models. A fully symmetrical boundary conditions have been applied to the models.

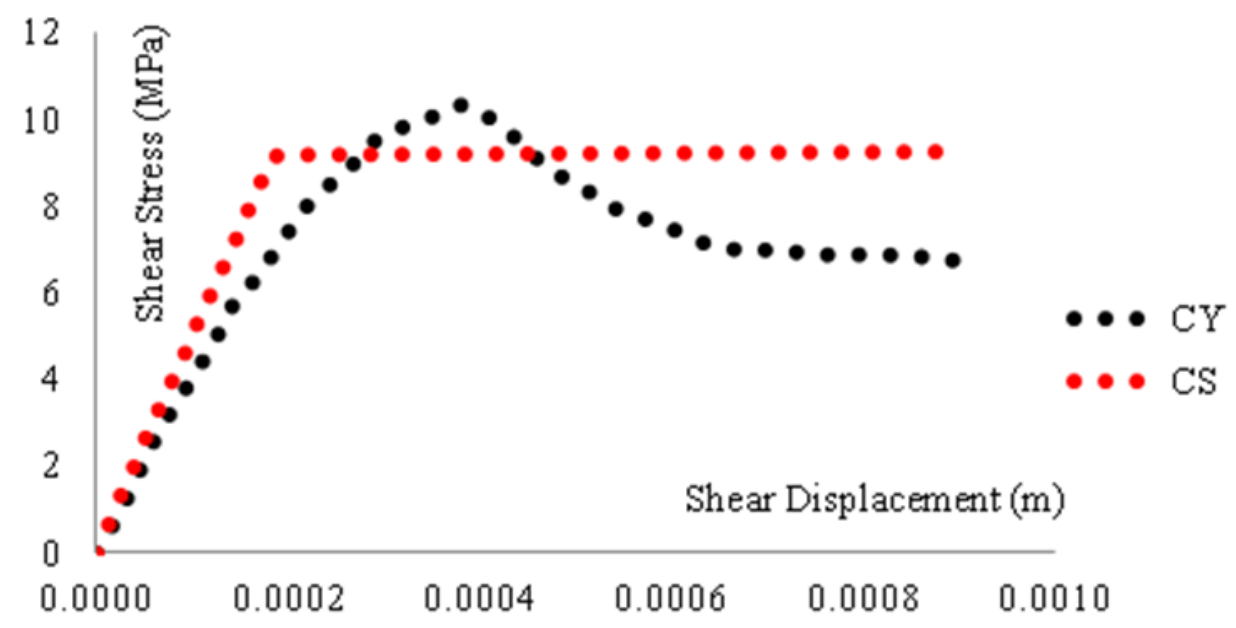

Figure 2 Stress-strain behaviours used in coal-rock interface (after Poeck et al. 2015)

Table 3 Joint properties used for the coal-rock interface (Poeck et al. 2015)

\begin{tabular}{lll}
\hline & Coulomb slip & Continuously yielding \\
\hline Shear stiffness (GPa) & 50 & 50 \\
\hline Normal stiffness $(\mathrm{GPa})$ & 50 & 50 \\
\hline Initial friction angle $\left(^{\circ}\right)$ & 20 & 40 \\
\hline Intrinsic friction angle $\left(^{\circ}\right)$ & - & 15 \\
\hline Joint roughness $(\mathrm{m})$ & - & 0.00015 \\
\hline Cohesion $(\mathrm{Pa})$ & 0 & - \\
\hline Dilation angle $\left({ }^{\circ}\right)$ & 0 & - \\
\hline Tensile strength $(\mathrm{Pa})$ & 0 & - \\
\hline
\end{tabular}




\section{$4 \quad$ Discussion about the results}

Figure 3 compares the in-plane horizontal stress distributions throughout the critical sections where it is situated near the edges in different material and joint properties. As is evident in Figure 2, the stress concentration would be over the entire model when there is a fixed interface as the allocated joint properties between the coal and overburden. This is because of the fact that there is no slip between the engaged surfaces. On the other hand, a local stress concentration was observed in both models where CS and CY joints were specified with slip joint properties between the major surfaces. Individually, the stress concentration is located at the edges of the model in which the slip direction was entirely restrained in that direction due to the possible particular geological structure of the mine. A comparison between the strain energy as well as the kinetic energy due to the different joint properties (i.e. the fix joint properties, the CS joint properties and the $\mathrm{CY}$ joint properties) is presented in Figures 4 to 6 . Figure 4 presents the relationship between the kinetic and strain energy when there is a fixed condition between the coal and overburden layers. As expected, it is evident from this figure that the strain energy is higher than (almost 4.5 times) the kinetic energy due to the lack of movement between the simulated layers, which indicates that the strain energy can be notably stored inside the strata layers rather than releasing as a kinetic energy due to the lack of the slip between different layers.

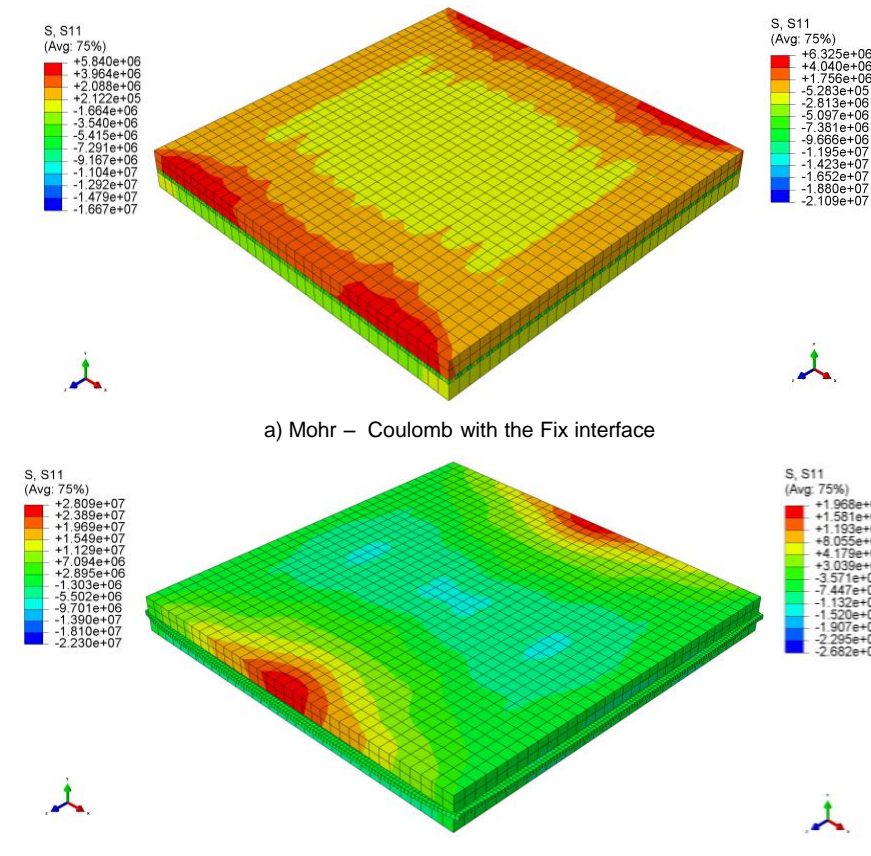

c) Mohr - Coulomb with the CS interface

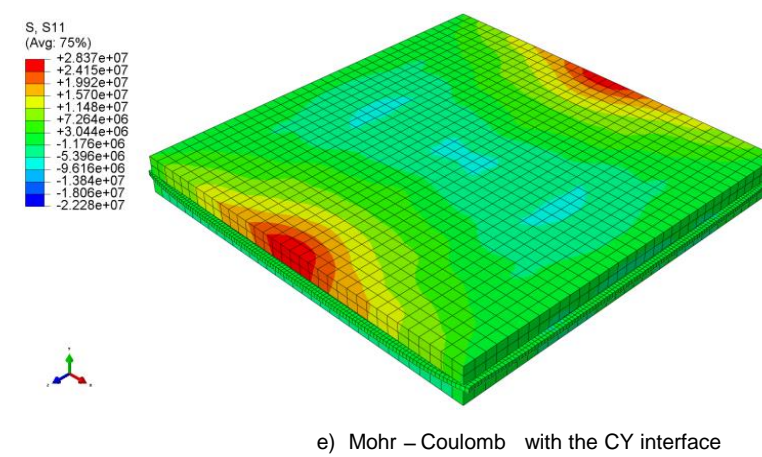

Figure 3 Stress distributions due to the different material and joint properties

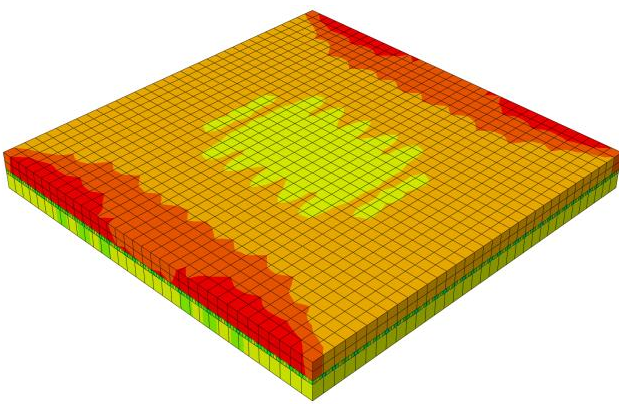

b) Mohr - Coulomb Hardening with the Fix interface

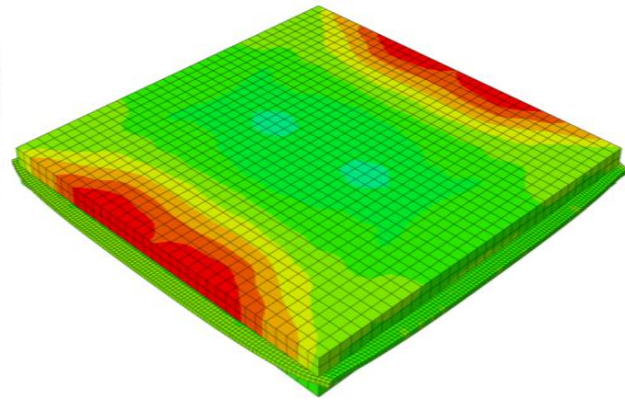

d) Mohr-Coulomb Hardening with the CS interface
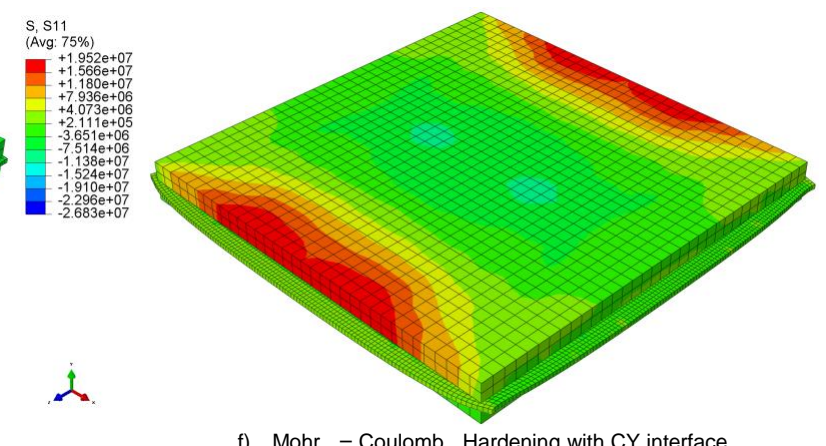

f) Mohr - Coulomb Hardening with CY interface 


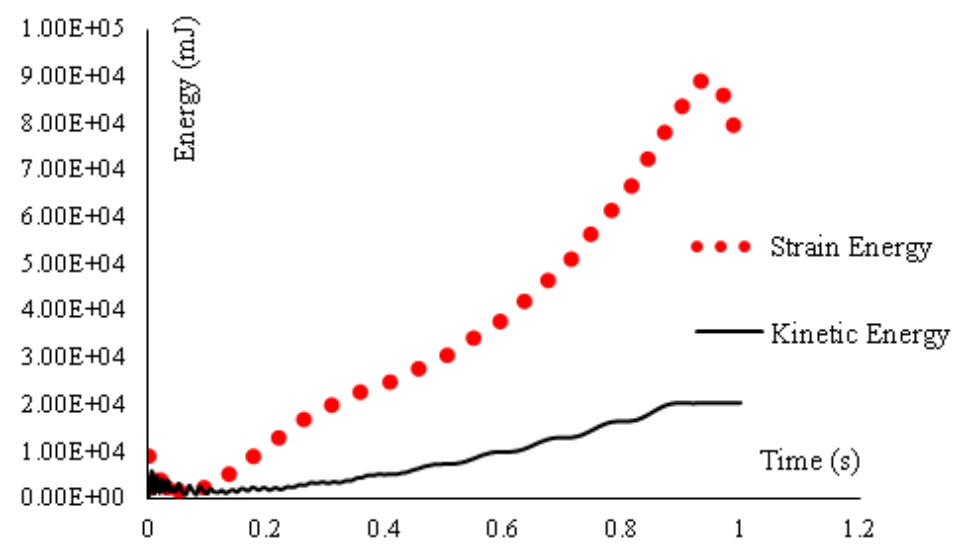

Figure 4 Strain and kinetic energies using fixed joint properties at different computing times

Both Figures 5 and 6, where the shear stresses between the joints is a function of slip between the layers, demonstrate that the kinetic energy is significantly higher (over 9.45 times) than the strain energy due to the movements between different layers regardless of the joint properties. This finding is important as it is verifies the mechanism of how the stored energy can be released into the different parts of the rock-coal interface.

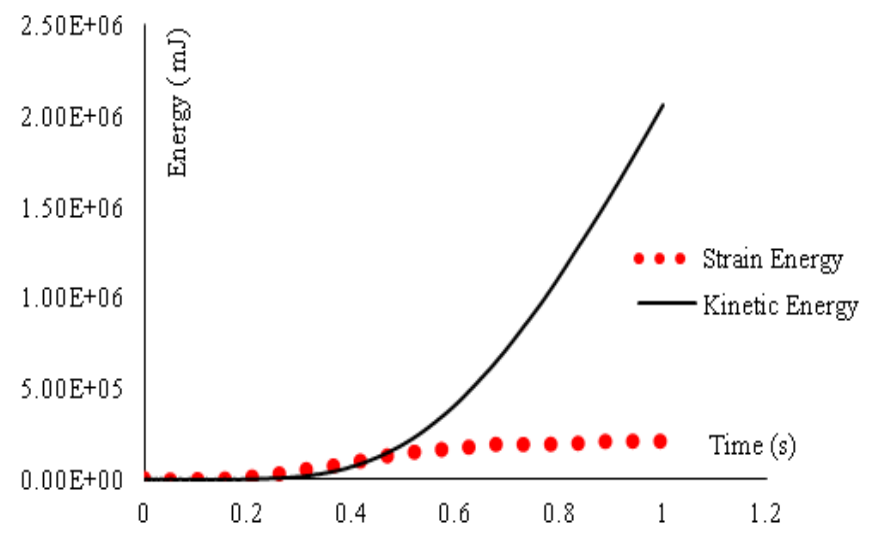

Figure 5 Strain and kinetic energies using CS joint properties at different computing times

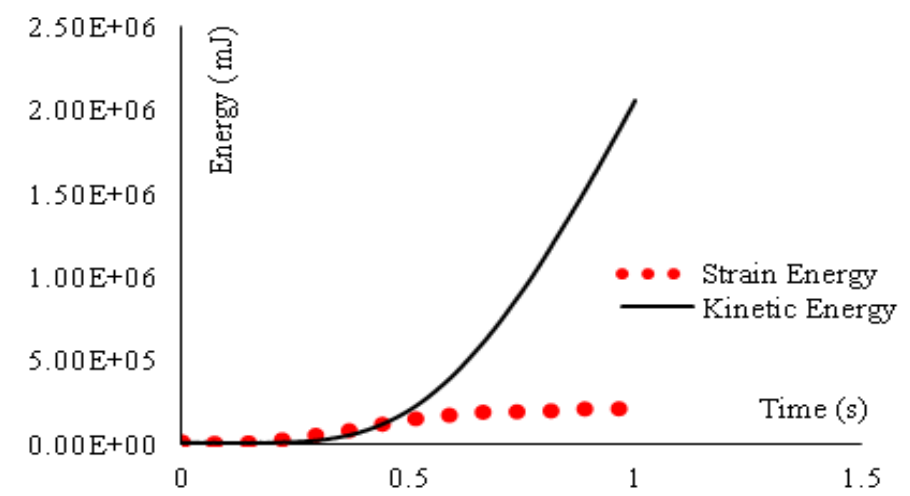

Figure 6 Strain and kinetic energies using $\mathrm{CY}$ joint properties at different computing times

Therefore, it is reasonable to conclude that in the burst-prone zones strata flexibility would be one of the critical considerations rather than only the strength and stiffness of the layers and joint properties. The kinetic energy which generally be transferred into the rock mass, can fully or partially be released from the strain energy which is stored in the rock mass. Thus, the source of the discussed strain energy may be significantly influenced by the geological structures (e.g. joint mechanical properties). Usually, the rock mass surrounding coal seams consists of the considerable discrete layers. Therefore, it is possible that a significant 
amount of this strain energy can either be converted to the active kinetic or passive thermal energy in different layers and it can lead to generating a large displacement as well as degradation of the rock mass which in turn might be highly destructive.

\section{Conclusion}

In this paper, an analytical procedure to calculate both strain and kinetic energy has been suggested. Furthermore, a comprehensive numerical method to compute the strain energy and kinetic energy before and during excavation has been systematically presented to assess the likelihood of a violent failure which could lead to coalburst occurrence. Simple mining layouts were modelled using different joint properties using varying material properties. It was numerically and analytically shown that the rock mass failure mode with different joint properties might be critically affected by the transmission of energy between the layers. The amount of the slip between the layers is partially either dependent on the joint properties or structural confinement in the free edges (for instance, the presences of geological structures such as faults, dykes, sandstone channels, joints. etc.). It can be concluded that how the slip in different directions can play a key role in releasing the stored energy in the different layers.

\section{References}

Cai, M 2013, 'Principles of rock support in burst-prone ground', Tunnelling and Underground Space Technology, vol. 36, pp. 46-56. Cook, NGW, Hoek, E, Pretorius, JPG, Ortlepp, WD \& Salamon, MDG 1966, 'Rock mechanics applied to the study of rockbursts', The Journal of the South African Institute of Mining and Metallurgy, vol. 66, pp. 435-528.

Cook, NGW 1983, 'Origin of rockbursts', in L Richards (ed.), Rockbursts; Prediction and Control, Institution of Mining and Metallurgy, London, pp. 1-9.

Dassault Systèmes Simulia Corp. 2012, ABAQUS/Explicit User's Manual, version 6.13EF-2, Dassault Systèmes Simulia Corp., Providence, Rhode Island.

Gong, QM, Yin, LJ, Wu, SY, Zhao, J\& Ting, Y 2012, 'Rock burst and slabbing failure and its influence on TBM excavation at headrace tunnels in Jinping II hydropower station', Engineering Geology, vol. 124, no. 1, pp. 98-108.

Li, S, Feng, XT, Li, Z, Chen, B, Zhang, C, \& Zhou, H 2012, 'In situ monitoring of rockburst nucleation and evolution in the deeply buried tunnels of Jinping II hydropower station', Engineering Geology, vol. 137-138, pp. 85-96.

Linkov, AM 1996, 'Rockbursts and the instability of rock masses', International Journal of Rock Mechanics and Mining Sciences \& Geomechanics Abstracts, vol. 33, no. 7, pp. 727-732.

Mitri, HS, Tang, B \& Simon, R 1999, 'FE modelling of mining-induced energy release and storage rates', The Journal of the South African Institute of Mining and Metallurgy, vol. 99, no. 2, pp. 103-110.

Mortazavi, A \& Alavi, FT 2013, 'A numerical study of the behavior of fully grouted rockbolts under dynamic loading', Soil Dynamics and Earthquake Engineering, vol. 54, pp. 66-72.

Nie, W, Zhao, ZY, Ning, YJ \& Guo, W 2014, 'Numerical studies on rockbolts mechanism using 2D discontinuous deformation analysis', Tunnelling and Underground Space Technology, vol. 41, pp. 223-233.

Ortlepp, WD \& Stacey, TR 1994, 'Rockburst mechanisms in tunnels and shafts', Tunnelling and Underground Space Technology, vol. 9, no. 1 , pp. 59-65.

Peng, SS 2008, Coal Mine Ground Control, Department of Mining Engineering, College of Engineering and Mineral Resources, Morgantown, West Virginia.

Poeck, EC, Zhang, K, Garvey, R \& Ozbay, U 2015, 'Energy concepts in the analysis of unstable coal pillar failures', Proceedings 34th International Conference on Ground Control in Mining, 28-30 July 2015, Morgantown, West Virginia, West Virginia University, Morgantown, pp. 105-111.

Ranzi, G, Gilbert, R 2015, Structural Analysis: Principles, Methods and Modelling, CRC Press, Boca Raton, Florida.

Ranzi, G, Dall Asta, A, Ragni, L \& Zona, A 2010, 'A geometric nonlinear model for composite beams with partial interaction', Engineering Structures, vol. 32, no. 5, pp. 1384-1396.

Salamon, MDG 1984, 'Energy considerations in rock mechanics; fundamental results', The Journal of the South African Institute of Mining and Metallurgy, vol. 84, pp. 233-246.

Sirait, B, Wattimena, RK, \& Widodo, NP 2013, 'Rockburst prediction of a cut and fill mine by using energy balance and induced stress', Procedia Earth and Planetary Science, vol. 6, pp. 426-434.

Tarasov, BG \& Randolph, MF 2008, 'Frictionless shear at great depth and other paradoxes of hard rocks', International Journal of Rock Mechanics and Mining Sciences, vol. 45, no. 3, pp. 316-328.

Wang, JA \& Park, HD 2001, 'Comprehensive prediction of rockburst based on analysis of strain energy in rocks', Tunnelling and Underground Space Technology, vol. 16, no. 1, pp. 49-57.

Wattimena, RK, Sirait, B, Widodo, NP \& Matsui, K 2012, 'Evaluation of rockburst potential in a cut-and-fill mine using energy balance', International Journal of the Japanese Committee for Rock Mechanics, vol. 8, no. 1, pp. 19-23.

Zhang, X, Feng, G, Kang, L \& Yang, S 2009, 'Method to determine burst tendency of coal rock by residual energy emission speed', Journal of the China Coal Society, vol. 34, pp. 1165-1168. 